\title{
Influence of Prior Knowledge Questions on Pupils' Performance in Reading Comprehension in Primary Schools in Kaduna, Nigeria
}

\author{
Hanna Onyi Yusuf \\ Department of Educational Foundations and Curriculum, \\ Ahmadu Bello University, Samaru-Zaria, Nigeria \\ E-mail: hannayusuf@yahoo.com \\ Sadiq Mohammed \\ Department of Arts and Social Science Education \\ Ahmadu Bello University, Zaria, Nigeria
}

Doi:10.7575/aiac.alls.v.4n.1p.134

URL: http://dx.doi.org/10.7575/aiac.alls.v.4n.1p.134
Received: 01/12/2012

Accepted: 03/01/2013

\begin{abstract}
This study was carried out to determine the influence of prior knowledge questions on pupils' performance in reading comprehension in primary schools in Kaduna, Nigeria. Two schools were used for the study. Ungwar Dosa primary school was used as the experimental school while Ungwar Rimi primary school was used as the control school. Thirty (30) primary five pupils from each of the two schools were used for the study. A total of sixty pupils were used for the study. A pre-test was administered on both groups of pupils before the commencement of teaching. A post-test was administered after six weeks of teaching. Data was analysed using mean, standard deviation and t-test. The findings revealed significant difference in the performance of pupils taught reading comprehension using prior knowledge questions. Based on the findings, teachers are encouraged among others, to use prior knowledge questions to motivate and stimulate pupils to use their relevant background knowledge to interpret and understand new information in their reading comprehension texts. Curriculum planners and textbook writers are encouraged to include prior knowledge questions as part of the activities pupils should be exposed to during reading comprehension lessons.
\end{abstract}

Keywords: prior Knowledge, performance, Nigeria

\section{Introduction/Background of the study}

In Nigeria's new National Policy on Education (2009) the inculcation of permanent literacy occupies number one position among the educational objectives of primary education. This, of course, is an indication of the primary of literacy in the curriculum for primary education. Reading plays an important role in the life of the individual and the society. The main purpose of reading is for understanding, interaction and comprehension of the author's experiences represented in symbols. Reading becomes meaningful only if a reader identifies and evaluates symbols and ideas. For pupils to achieve the above mentioned intellectual tasks, it is important to develop reading strategies as an aspect of the reading process.

In recent years, many studies have been carried out on reading strategies and skills. Most researchers in their findings have attributed pupils' poor performance to lack of appropriate methods of teaching reading. For instance, Oyetunde (2009) recognised the fact that the root cause of poor reading in the primary school is the method of teaching reading. Hence, in his words, "a comprehensive examination of the teaching of reading in the primary school is required".

The research is also motivated by the observation made, by this researcher during one of her visit to some primary schools in Kaduna, to conduct a trial test of some instruments for assessing academic achievement. This researcher discovered with dismay that majority of the pupils could not read the passages given to them let alone answer the questions. The situation was so bad that this researcher feet she should investigate the cause of this problem. By assessing the influence of prior knowledge questions on pupils' reading comprehension perhaps this researcher will be able to advise teachers on possible ways of improving the teaching of reading comprehension.

Experimental background has been shown to have extra tremendous influence on reader's ability to understand meaning as intended by the author in a written communication. Adams \& Bruce (1982), Moon (1981), Smith (1978) have all, to varying degrees, stressed by importance of experimental background d to a reader's success. Smith (1973) and Stervens (1977) say a student's apparent reading problem is often a problem of insufficient background. Smith (1973) argued that comprehension and learning proceed by attaching the 'new' to the 'old'. In the word of Adams and Bruce (1982:37). Comprehension is the use of prior knowledge. Without prior knowledge, a complex object such as a text, is not just difficult to interprete, strictly speaking, it is meaningless. 
The above has clearly shown that experiential background is indispensable in the comprehension of a text. It has also shown that researchers need prior knowledge to be able to comprehend a given text. It is against this background that this researcher seeks to find out the influence of prior knowledge questions on pupils' performance in reading comprehension in primary schools in Kaduna, Nigeria.

This, however, is often not the case. Most pupils, especially those about to enter JSS one, are deficient in a basic reading skills. Some of then cannot even read a word of English at primary six, and there is ample evidence that a high proportion of pupils are at a stage when they need further developmental reading instruction. Unfortunately, at this level which is supposed to be the bedrock of all subsequent levels of education, there is no reading instruction, except for 'comprehension lessons' in their English classes which as Oyentude (1987), and Umolu $(1991,1996)$ observe serve as a test of reading compression rather than instruction. Teachers at this basic foundation level unfortunately lack training in reading and reading instruction, (Unoh 1982 and Umolu, 1996).

\section{State of the problem}

In general, many factors influence the comprehension of textbooks. These include socio-cultural factors such as home background or experience at home, peer influence such as the absence of reading by the society. There are also influences such as the absence of reading culture; linguistic factors such as the level of vocabulary and the syntactic and semantic difficulty of the textbooks; psychological factors such as motivation, interest and prior knowledge and pedagogical factors such as teacher training, methods used in teaching reading and instructional materials (Odumuh 1997).

Studies in the first language (Devine, 1981, Carroll 1972) regarding the influence of different factors on reading achievement and comprehension have revealed that the situation is not same in the second language situation. Factors, which have been found to be significant in the first language situation, may not necessarily account for reading difficulties in a second language situation. For instance, many studies in the first language have emphasized the importance of home background, family size and parental concern for their children's progress in school (Douglass, 1964; and Thorndike, 1973). In a second language situation (such as English in Nigeria), there are additional factors such as cultural factors, which impede the learners' reading achievement. Unoh (1980) identifies the reading problems of secondary school students as slow, poor comprehension, poor recall, inadequate vocabulary, and inadequate reading interest. Cross-cultural studies which have tried to compare the performance of Nigerian Students with that of their counterparts in developed countries depict a gloomy picture (Ayodele, 1984).

The influence of some of the factor may be greater in real terms today, given the condition of educational institutions in today's Nigeria. These factors include, according to Odumuh (1997), lack of qualified teachers, poor classroom condition, lack of reason materials, large class size and little or no encouragement from parents, home, teacher and peer group. A factor which perhaps could contribute to this persistent reading problem and which has not received much attention is the method used in teaching reading and this is the focus of this study. Most studies in reading comprehension so far conducted in Nigeria have concentrated on examining reading difficulty of students at the primary and junior secondary levels with focus on the texts being used. However, there are reasonable grounds to suspects that other non-text factors, such as pedagogical factors, affect reading comprehension as well. Literature search reveals that pedagogical factors have relieved little or no attention in Nigeria (Abe, 1983, Abiri, 1983, Oyetunde \& Umolu, 1989). The absence of such crucial information constitutes a problem. This has motivated the present study. The study is also based on the premise that the comprehension of a textbook depends on the interaction of a number of factors, which can be broadly categorized into four: socio-cultural, linguistic, psychological and pedagogical factors. The influence of these factors on the reader's comprehension especially in a second language situation is uncertain. There is, therefore, the need to ascertain the extent to which pedagogical factors influence reading comprehension. To this end, this study will focus on the influence of prior knowledge questions on pupils' performance in reading comprehension in primary schools in Kaduna, Nigeria.

\section{Review of related Literature}

Research findings have shown that learning proceeds primarily from prior knowledge, and only secondarily from the presented materials. Prior knowledge can be at odds with presented material, and consequently, learners will distort presented material. Neglect of prior knowledge can result in the audience learning something opposed to the educator's intentions, no matter how ell those intentions are executed in an exhibit, book, or lecture.

To help people make the most of a new experience, educators need to understand how prior knowledge affects learning. To the child who does not yet understand heat and temperature, for instance no quick explanation can possibly resolve the contradiction between the hot desert and the warm wool; it takes weeks or years for this understanding to emerge (Lewis, 1991).

Prior knowledge forces a theoretical shift to viewing learning as "conceptual change." (Strike \& Posner, 1985; West \& Pines, 1985). Previously learning was considered a process of accumulating information of experience. Prior knowledge is the bane of transmission-absorption models of learning. More absorption cannot account for the revolutionary changes in thought that must occur. The child simply can't absorb knowledge about wool, because prior knowledge about heat renders incoming ideas nonsensical.

Prior knowledge exists not only at the level of "concepts," but also at the levels of perception, focus of attention, procedural skills, modes of reasoning, and beliefs about knowledge. Trowbridge and McDermott (1980) studied perception of motion. Students perceive equal speed at the moment when two objects pass, whereas scientists observe a 
faster object passing a slower one. Anzai and Yokohama 91984), Larkin (1983), and Chi, feltovich, and Glaser (1990) studied how students perceive physics problems and found they often notice superficial physical features, such as the presence of a rope, whereas scientists perceive theoretical-relevant features, such as the presence of a pivot point. Larkin, McDermott, Simon and Simon (1980) studied students' solutions to standard physics problems and found that students often reason backwards from the goal towards the known facts, whereas scientists often proceed forward from the given facts to the desired unknown. Similarly, Kuhn (Kuhn, Amsel, \& O'Loughlin, 1988) studied children's reasoning at many ages and found that children only slowly develop the capability to coordinate evidence and theory in the way scientists do. Finally, Songer (1988) and Hammer (1991) studied students beliefs about the nature of scientific knowledge. They found that student sometimes have beliefs that foster attitudes antagonist to science learning.

In summary, prior knowledge comes in divers forms. It affects how students interpret instruction. While it may not prevent them from carrying out procedures correctly, it frequently leads to unconventional and unacceptable explanations. Prior knowledge is active at levels ranging from perception to conception to beliefs about learning itself. Moreover, its effects are widespread through lay and professional population, from young children through to adults, and from low to high ability students.

\subsection{Implication of Prior Knowledge: Learning as Conceptual Change}

The overwhelming weight of the evidence of the importance of prior knowledge has formed informed educators to fundamentally change the way science is taught. Perhaps because learners are more likely to construct an interpretation that agrees with prior knowledge, and consequently disagrees with the viewpoint of the teacher. Thus, the effects of prior knowledge require a change from the view that learning is absorption of transmitted knowledge, to the view that learning is conceptual change (Resnick, 1983; Champagne), Gunstone, \& Klopfer, 1985). Over time, learners need to accomplish the rarest form of change, a paradigm shift in their basic assumptions about the natural world, and the accompanying ways they see, conceive, and talk about the world. Conceptual change is a process of transition from ordinary ways of perceiving, directing, attention, conceptualizing, reasoning, and justifying. Slowly learners transform prior knowledge to accommodate new scientific ideas (Posner, Strike, Hewson, \& Gertzof, 1982).

\section{Objective of the study}

The objective of the study is to determine the influence of prior knowledge questions on pupils' performance in reading comprehension in primary schools in Kaduna, Nigeria.

\section{Research questions}

To what extent does prior knowledge questions have influence on pupils' reading comprehension in primary schools in Kaduna, Nigeria?

\section{Hypothesis}

Prior knowledge questions have no significant influence on pupils' reading comprehension in primary schools in Kaduna, Nigeria.

\section{Methodology}

The subjects of the study were sixty (60) pupils from two primary schools in Kaduna i.e 30 pupils from Ungwar Dosa primary school and 30 pupils from Ungwar Rimi Primary school. The two schools were located far apart to minimise interaction. The two teachers who taught the classes were judged to be comparable in teaching ability on the basis of their equivalent qualification as Nigeria certificate in Education (NCE) holders. Ungwar Dosa primary school was used as the experimental group while Ungwar Rimi Primary school was used as the control school. The pupils in both schools were taught for eight (8) weeks. Three (3) reading comprehension tests were taken from the pupils' English Language text book titled Comprehensive English by Lantern publishers. The comprehension questions were designed by the researcher so as to include some literal, inferential and critical questions.

\subsection{Research Design}

A quasi experimental non randomization control design was used. A pre-test was administered prior to the commencement of teaching in order to establish the homogeneity of the pupils. A post test was administered after eight (8) weeks of teaching to determine any probable changes in the experimental group. More questions were included in the post test since it was felt that by the end of the eight (8) weeks of teaching the pupils would have been more familiar with the passage.

\subsection{Instrumentation}

The instruments used for the study were reading comprehension passages from which test items were drawn demanding pupils use of prior knowledge experience. Six passages were carefully selected from the Comprehensive English Book 4 text in use in the schools. The passages were selected because the subject matter were of interest to both gender. The content of the passage was educative and informative and adequately provided some of the needed items for the tests.

\subsection{Administration of instruments}

A pre-test on three passages was administered to both control and experimental groups to establish the homogeneity of the pupils. The experimental group was taught reading comprehension using prior knowledge questions for eight (8) weeks while the control group had their normal reading comprehension lessons taught by their teacher. 
A post-test (on the same three passages) was administered on the two groups after eight weeks of teaching to determine the influence of prior knowledge questions on the performance of second language learners in reading comprehension. T-test was used to test for significant difference in the performance of pupils from both groups.

\subsection{Treatment}

The teacher

i) begins reading activities with what pupils already know from home community, and school.

ii) facilitates the reading and understanding of the comprehension passage by introducing prior knowledge questions. Questions such as what does the title of the passage suggest? What does the title remind you of? Does it remind you of a similar experience?

iii) designs instructional activities that are meaningful to pupils in terms of local community norms and knowledge.

iv) acquires knowledge of local norms and knowledge by talking to pupils' parents or family members, community members, and by reading pertinent documents.

v) assists pupils to connect and apply their learning to home and community

vi) encourages pupils to utilize their prior knowledge and skills as a foundation for new knowledge.

vii) assists pupils to make connections between what they already know and newly acquired knowledge in order to strengthen and increase pupils' engagement with learning activities.

Table 1. Presentation of test scores for pre-test for experimental and control groups.

\begin{tabular}{|l|l|l|l|l|}
\hline \multicolumn{1}{|c|}{ Test } & N & DF & Mean & SD \\
\hline Pre-test experimental Group & 30 & 29 & 42.5 & 10.12 \\
\hline Pre-test control & 30 & 29 & 41.3 & 9.91 \\
\hline
\end{tabular}

A careful observation of table 1 above shows that the pupils' initial point of entry before the commencement of treatment is at par. The difference in the standard deviation of pupils' scores in the experimental and control group is very little. One can therefore say that pupils in the two groups are of equivalent reading ability at the point of entry.

Table 2. Presentation of test scores for post-test for both experimental and control groups

\begin{tabular}{|l|l|l|l|l|}
\hline \multicolumn{1}{c|}{ Test } & N & DF & Mean & SD \\
\hline Post-test experimental & 30 & 29 & 78.50 & 12.12 \\
\hline Pre-test control & 30 & 29 & 51.50 & 7.80 \\
\hline
\end{tabular}

Table 2 shows that the mean and standard deviation of the experimental group appears to be higher than that of the control group. This is probably because of the prior knowledge questions. The control group was not exposed to any of such activities. Therefore one could say that the schemata of the control group was not properly activivated in the reading comprehension passages as it did for pupils in the experimental group.

Table 3. Presentation of test scores for pre-test and post-test for experimental and control groups.

\begin{tabular}{|l|l|l|l|l|l|l|}
\hline \multicolumn{1}{|c|}{ Test } & N & DF & Mean & T-cal & T-crit & Decision \\
\hline Experimental Group & 30 & 29 & 42.5 & & & \\
\hline Experimental Group Post test & 30 & 29 & 78.50 & 11.273 & 2.201 & $\begin{array}{c}\text { Hypothesis } \\
\text { rejected }\end{array}$ \\
\hline Control group pre-test & 30 & 29 & 51.50 & 7.062 & 2.069 & \\
\hline Control group post-test & 30 & 29 & 51.50 & 7.062 & 2.069 & \\
\hline
\end{tabular}

Table 3 shows that the calculated value (7.062) is greater than the critical value of (2.201) at degree of freedom 29 and at 0.05 level of significance. Hence the null hypothesis is rejected, meaning prior knowledge questions influence pupils' performance in reading comprehension.

\section{Discussion of Findings}

There is a general increase in the level of involvement and participation of pupils in the experimental group probably because of the activities pupils were engaged in. Pupils and teachers were actively involved in the discussion of the passages before, during and after the passages were read. In the lessons that were observed, pupils generally showed 
keen interest in the discussion. Each pupil was eager to share his/her own experiences with the class. The pupils that were taught in the control group were not exposed to any prior knowledge questions. Pupils performance in the tests were generally low not because they lacked ability or because they are poor readers but probably because pupils were not exposed to prior knowledge questions that could stimulate class discussions. They were passive most of the time.

It is also interesting to note that the pupils in the experimental group performed very well in literal inferential and critical questions. Their scores were higher than those of the control group. This goes to confirm the studies of Odumuh (197), Oyetunde (2009), Smith et al (1993) Simon \& Simon (1980) and Chi,feltorich and Glaser (1990) which all point to the fact that the use of prior knowledge questions helps pupils to select important information from the text and also encourages them to make use of their natural abilities to make and confirm predictions as they read and perform reading tasks. Teachers should therefore try as much as possible to design instructional activities that will require pupils to make connections to strengthen newly acquired knowledge that will increase pupils engagement with learning activities. Pupils stand to benefit a lot if they are actively engaged or involved in class discussions/ activities with their teachers.

\section{Conclusion}

Based on the findings of this research the pupils taught reading comprehension using prior knowledge questions gained more than those taught without prior knowledge questions. As a matter of fact, pupils were able to use their relevant background knowledge to interpret and understand new information in their reading comprehension texts.

\subsection{Recommendations}

The following recommendations were made based on the findings of the research.

I. Teachers should be encouraged to use prior knowledge questions before, during and after every reading comprehension passage.

II. Curriculum planners should be encouraged to include prior knowledge questions as part of the activities pupils should be exposed to in every reading comprehension lesson.

III. Textbook writers should include prior knowledge questions as part of pupils reading comprehension exercises. This will help pupils to link the new information with what they already know.

IV. Teachers should encourage pupils to participate actively in class discussions by responding positively to the prior knowledge questions in the course of reading the comprehension passages.

V. Teachers should always construct prior knowledge questions that will assist pupils in making use of their relevant schemata to facilitate the understanding of the reading texts.

\section{References}

Abiri J. O (1983) Literacy and Reading in Nigeria, Problems and Method of Teaching initial reading in English and Nigeria languages Unoh, Omojuwa and Crow (Eds).Mc Milan, Lagos.

Anzai, Y. \& Yokohama, T. (1984. Internal models in physics problem solving. Cognition and Instruction, 1, 397-450.

Carroll, J.B. (1972) "Defining Language, comprehension: some speculation" J. F. Carroll and R. O. Freele (Eds) Language comprehension and the acquisition of knowledge. Washington DC: Winston.

Champagne, A.B., Gunstone, R.F., \& Klopfer, L.E. (1985). Consequences of knowledge about physical phenomena. In L.H (1985). Consequences of knowledge about physical phenomena. In L.H.T. West and A.L. Pines (Eds.), Cognitive Structure and Conceptual Change. New York: Academic Press.

Chi, M.T.H., Feltovich, P.J., \& Glaser, R. (1980). Categorization and representation of physics problems by novices and experts. Cognitive Science, 5, 121-152.

Devine, J. (1981). Developmental patterns in native and non-native reading acquisition. In S. Hudelson, (Ed.). Learning to Read in Different Languages, (Linguistics and Literacy Series 1). (ERIC Document Reproduction Services No.ED 198 744).

Hammer, D.M. (1991). Defying commonsense: Epistemological beliefs in an introductory physics course. Unpublished doctoral dissertation, University of Califonia, Berkeley.

Knorr, Karin. (1981). The manufacture of knowledge: An essay on the constructive and contextual nature of science. Oxford: Pergammon Press.

Kuhn, D., Amsel, E., \& O’Loughlin, M. (1988). The development of scientific thinking skills. San Deigo, CA: Academic Press.

Larkin, J,H., McDermott, J., Simon, D.P., \& Simon, H. (1980). Expert and novice performance in solving physics problems. Science, H. (1980). Expert and novice performance in solving physics problems. Science, 208, 1335-1342.

Larkin, J.H (1983). The role of problem representation in physics. In D. Gentner \& A.L. Stevens (Eds), mental models. Hillsdale, NJ: Earbaum.

Lewis, E.L. (1991). The process of scientific knowledge acquisition of middle school students learning thermodynamics. Unpublished doctoral dissertation. University of Califonia, Berkeley.

McDermott, J.J. (1981). The philosophy of John Dewey. Chicago: University of Chicago Press. 
Odumuh, T. O. (1997) Effect of motivation and prior knowledge on reading comprehension: A study of senior secondary school students in Gwagwalada area council of Federal Capital Territory unpublished Ph.D Dissertation, Faculty of Education A.B.U., Zaria.

Oyetunde T.O (2009). "Beginning Reading Scheme" Empowering teachers to help their pupils become good teachers. Jos: LECAPS publishers. Shertogenboch

Posner, G.J, Strike, K.A., Hewson, P.W., \& Gertzog, W.A. (1982). Accommodation of a scientific conception: towards a theory of conceptual change. Science Education, 66(2), 211-227.

Posner, G.J. \& Gertzog, W.A. (1982). The clinical interview and the measurement of conceptual change, science Education, 66, 195-209.

Resnick, L.B. (1983). Mathematics and science learning: a new conception. Science, 220, 477-478.

Simon, H.A. \& Kaplan, C.A. (1989). Foundations of Cognitive Science. Cambridge, MA: MIT Press.

Smith, J.P., diSessa, A.A., Roschelle, J. (1993). Misconceptions reconceived: A constructivists analysis of knowledge in transition. Journal of the Learning Sciences, 3(2), 115-163.

Songer, N.B. (1989). Promoting integration of instructed and natural world knowledge in thermodynamics. Unpublished Doctoral Dissertation. University of Califonia, Berkeley.

Thorndike, R. L. (1973). Reading Comprehension Education in Fifteen Countries: An Empirical Study. Stockholm: International Association for the Evaluation of Educational Achievement (IEA).

Trowbridge, D.E. \& McDermott, L.C. (1980). Investigation of student understanding of acceleration in one dimension. American Journal of Physics, 50, 242-253. 